\title{
'Milkshake should not be exempt from sugar tax'
}

\author{
The Faculty of General Dental \\ Practice (FGDP[UK]) says \\ high sugar milk-based drinks \\ should not be exempt from the \\ Government's planned sugar tax. \\ Responding to a Treasury consul- \\ tation on the tax's implementa- \\ tion, the FGDP(UK) argues that \\ despite the nutritional benefits of \\ milk, the large amount of added \\ sugar in flavoured milk drinks \\ means they are 'likely to carry far \\ greater disbenefits than benefits to \\ children's health'
}

The FGDP(UK) recognises the nutritional importance of milk, particularly for young children. However, the Faculty points out that a 300-500 ml bottle of milkshake will typically contain at least the $35 \mathrm{~g}$ (nine teaspoons) of sugar found in a $330 \mathrm{ml}$ can of cola, and in many cases over $60 \mathrm{~g}$ (15 teaspoons) of sugar - over twice the recommended maximum total sugar intake of $24 \mathrm{~g}$ a day for 7-10-year-olds, and three times the $19 \mathrm{~g}$ a day maximum recommended for 4-6-year-olds.

The new Government has reaffirmed its commitment to the tax, which will charge manufacturers 18 pence per litre for drinks with total sugar content above $5 \mathrm{~g}$ per $100 \mathrm{ml}$, and 24 pence per litre for those above $8 \mathrm{~g}$ per $100 \mathrm{ml}$.

However, drinks containing 75\% milk are to be exempt, and the FGDP(UK) says this proportion is far too low, as most high

\section{Home Office rules out X-rays for asylum seekers}

\section{On 20 October the British Dental}

Association (BDA) welcomed news that the Home Office has followed its advice - and ruled out unethical and ineffective X-rays to establish the age of child asylum seekers.

A day earlier the BDA had condemned suggestions that $\mathrm{X}$-rays could be used to offer definitive proof on whether children from the Calais refugee camp are under 18 years of age, describing the tests as ineffective, inappropriate and unethical.

Wisdom teeth can erupt from the age of ten, and do not appear in some adults. These X-rays can therefore only provide an estimate of a patient's age range - while requiring them to undergo a medical procedure without their informed consent and without any planned clinical benefit.

The BDA has engaged on the issue for over a decade, and has resisted calls from successive governments to make this practice mainstream.

Judith Husband, Chair of the BDA's Education, Ethics and the Dental Team Working Group said: 'We're pleased the Home Office has finally ruled out the use of dental X-rays on child asylum seekers. It draws a line under ten years in which ministers have kept flirting with an eyecatching, but ultimately ineffective, policy.

'Dental X-rays were never going to be a silver bullet for verifying age. They aren't cheap, they aren't simple, and at the end of day they don't provide definitive results.'

\section{BDA branch events}

\begin{abstract}
Western Counties
Western Counties Branch AGM will be held at The Hankridge Arms, Hankridge Way, Waterside, Taunton, TA1 2LR at

7 pm on Monday 7 November. To confirm your attendance or to offer apologies please contact Alun Rees, alunrees@mac.com.

\section{Central Counties}

Central Counties Branch AGM will be held on Wednesday 23 November 2016 in Lecture
\end{abstract}

Room One, Birmingham Dental Hospital, 5 Mill Pool Way, Birmingham, B5 7EG. Registration and light refreshments from 7 pm, AGM 7.30 pm. The AGM will be followed by a Political Update from Eddie Crouch, and Invisalign with Gillian Cottam. The course will attract two hours' CPD. To confirm your attendance or offer apologies contact Tracey Broadley, 15 Garganey Court, Kidderminster, Worcestershire, DY10 4UE or email Tracey.Broadley@sky.com.

\section{Northern Counties \\ The Northern \\ Counties Branch \\ Annual General \\ Meeting will be held \\ on Thursday 8 December at the Tyneside Cinema, Newcastle Upon Tyne, NE1 6QG. Welcome drinks and buffet from $7 \mathrm{pm}$. \\ To confirm attendance or offer apologies please contact James Field james.field@ newcastle.ac.uk.}

